\title{
PENINGKATAN KEMAMPUAN KOMUNIKASI IBU MENGELOLA EMOSI ANAK USIA SEKOLAH MELALUI TERAPI KELOMPOK ASSERTIVENESS TRAINING
}

\author{
Evin Novianti $^{1,2^{*}}$, Budi Anna Keliat ${ }^{3}$, Tuti Nuraini ${ }^{3}$, Herni Susanti $^{3}$ \\ 1. FIKes PSIK Universitas Pembangunan Nasional Veteran Jakarta, Jakarta 12450, Indonesia \\ 2. Program Studi Magister Fakultas Ilmu Keperawatan Universitas Indonesia, Depok 16424, Indonesia \\ 3. Fakultas Ilmu Keperawatan Universitas Indonesia, Depok 16424, Indonesia \\ *Email:enov78@yahoo.co.id
}

\begin{abstract}
Abstrak
Anak usia sekolah yang belum mampu mengolah masalahnya dengan tepat, rentan berperilaku emosional. Tujuan penelitian memperoleh gambaran pengaruh terapi kelompok Assertiveness Training (AT) terhadap kemampuan komunikasi ibu mengelola emosi anak usia sekolah. Sampel pada kelompok intervensi dan kontrol masing-masing 32 orang. Hasil penelitian memperlihatkan bahwa peningkatan kemampuan komunikasi asertif ibu pada kelompok yang mendapat AT meningkat secara bermakna $(\mathrm{p}<0,05 ; \alpha=0,05)$. Pada kelompook ibu yang tidak mendapat AT, kemampuan komunikasi ibu menurun secara bermakna ( $p<0,05 ; \alpha=0,05)$. Kemampuan anak mengelola emosi meningkat bermakna $(p<0,05 ; \alpha=0,05)$ yang ibunya mengikuti AT, sedangkan pada kelompok yang ibunya tidak mendapat AT menurun bermakna $(p<0,05 ; \alpha=0,05)$. Terapi ini direkomendasikan pada pelayanan kesehatan di masyarakat khususnya anak usia sekolah.
\end{abstract}

Kata kunci: Kemampuan komunikasi orangtua, mengelola emosi, terapi kelompok Assertiveness Training

\begin{abstract}
At school age, children may not be able to treat the problem appropriately, behave emotionally vulnerable. The research objective picture of the influence of group therapy get assertiveness training (AT) on the communication skills to manage emotions mothers of school-age children. Samples in the intervention group and the control of each 32 people. The results showed an increase in assertive communication skills mothers in the group receiving AT increased significantly $(p<0.05 ; \alpha=$ $0.05)$. In kelompook mothers who did not receive AT, communication skills mothers were significantly decreased ( $p<0.05 ; \alpha=$ $0.05)$. Child's ability to manage emotions increased significantly $(p<0.05 ; \alpha=0.05)$ whose mothers followed the AT, whereas in the group whose mothers did not receive AT decreased significantly $(p<0.05 ; \alpha=0.05)$. This therapy is recommended for health care in the community, especially school-age children.
\end{abstract}

Keywords: Ability of parent communication, arrange emotion, Assertiveness Training group therapy

\section{Pendahuluan}

Setiap anak akan menjalani masa tumbuh kembangnya, yang tanpa disadari berpengaruh terhadap perkembangan jiwa di masa yang akan datang (Hartono, 2009). Masa perkembangan yang paling mencolok terjadi pada masa sekolah, yaitu anak sudah mulai memasuki sekolah dasar, suatu kegiatan yang menuntut kemampuan sosial anak. Hal ini diperkuat oleh pernyataan Hurlock (2008), menyatakan bahwa setiap upaya anak memenuhi tugas tumbuh kembangnya, anak kerap mendapat stressor baik secara fisik, psikologis maupun sosialnya.
Penelitian yang dilakukan oleh Ibung (2008) menemukan bahwa diantara tingkatan tugas tumbuh kembang seseorang, rentang usia sekolah (6-12 tahun) yang paling rentan mendapat stres, yaitu kemampuan anak dalam mengatasi masalahnya masih terbatas sedangkan interaksi sosial yang semakin luas menuntutnya dapat berperilaku sesuai keingingan orang lain (teman, guru, orangtua, saudara, dll). Pada usia sekolah selain pertumbuhan fisik anak yang berkembang pesat, juga berkembang emosi anak, namun di usia sekolah ini, anak belum mampu mengolahnya secara tepat sehingga anak lebih rentan untuk berperilaku emosional. 
Faktor dari dalam dan luar anak mempengaruhi munculnya emosi anak. Apabila anak mengalami tuntutan dari berbagai pihak ditambah lagi dengan kurangnya pengalaman menyelesaikan konflik, emosi yang muncul dapat saja berupa ledakan emosi atau bahkan menutup rapat-rapat emosi tersebut maka anak cenderung terlihat suka membantah, protes, tidak mau mengikuti keinginan orangtua. Agar situasi tersebut tidak berlangsung terusmenerus, dibutuhkan penataan lingkungan sekitar anak yaitu orangtua, guru, pengasuh, teman, nenek, kakek, kakak, atau adik.

Orangtua merupakan kelompok sosial pertama yang menjadi pusat identifikasi anak, orangtua adalah orang yang paling banyak menghabiskan waktu dan berinteraksi dengan anak (Hurlock, 2008). Secara sadar atau tidak perilaku mereka direkam, diresapi dan ditiru dan menjadi kebiasaan bagi anak. Hal ini dikarenakan anak mengidentifikasikan diri pada orangtua sebelum mengadakan identifikasi dengan orang lain.

Hasil penelitian Papalia dan Olds (1990, dalam Ramadhani, 2008) menegaskan bahwa komunikasi anak dan ibu telah terjadi pada bulan-bulan pertama usia anak. Dalam hal ini orang tua terutama ibu yang paling paham dengan kemampuan anak mereka dalam menyelesaikan masalahnya seharihari, karenanya dibutuhkan keterampilan dan kemampuan mengelola emosinya.

Kemampuan orang tua (terutama ibu) yang harus dimiliki untuk mengelola emosi anak menurut Gottman dan DeClaire (2008) adalah kemampuan menyadari emosi anak, mengenali emosi sebagai peluang untuk akrab, mendengarkan si anak untuk memberi label emosi dengan kata-kata dan menentukan batas-batas sambil menolong si anak memecahkan masalah. Cara efektif untuk mencapai kemampuan tersebut adalah dengan berkomunikasi secara asertif pada anak. Asertif mengandung arti kata ketegasan dan kebebasan mengekspresikan emosi tanpa rasa takut (Ramadhani, 2008). Sedangkan komunikasi asertif adalah komunikasi yang mendorong anak berkembang secara optimal, baik fisik maupun psikis, mengandung pesan yang jelas, positif, terbuka, dapat dipercaya dan tidak menghakimi anak (Ramadhani, 2008).

Orang tua perlu berlatih berkomunikasi secara asertif di rumah, yaitu orangtua sebagai pelatih mengelola emosi anak. Latihan tersebut harus dilakukan berulang-ulang dan diterapkan ke anak, sehingga memerlukan bimbingan dan arahan secara intensif dari seorang terapis. Pelatihan yang diperlukan oleh orangtua adalah dalam bentuk Assertiveness Training (AT) (Stuart \& Laraia, 2005).

Terapi AT melatih orang tua yang mempunyai anak usia sekolah (6-12 tahun) menghadapi masalahmasalah emosional anak sekolah. Terapi AT merupakan terapi kelompok yang memberi kesempatan anggotanya untuk saling berbagi pengalaman, saling membantu dan menyelesaikan masalah. Sasaran dalam terapi AT bukan hanya aspek kognitif saja tapi juga aspek psikomotor dan sikap. Perubahan ketiga ranah tersebut akan tercapai apabila anggota kelompok berperan aktif selama proses melalui bermain peran setelah melihat demonstrasi/ modelling beberapa ketrampilan asertif. Demonstrasi lebih efektif apabila berupa persoalan-persoalan yang realistis dan sering terjadi pada anggota kelompok. Melalui terapi AT kemampuan asertif orang tua dilatih dan diterapkan di masa sebelum beranjak remaja, dilakukan di komunitas masyarakat untuk mengatasi risiko terjadinya gangguan jiwa di masa yang akan datang melalui terapi AT.

Terapi AT pada keluarga sehat merupakan upaya promotif pelayanan kesehatan jiwa di masyarakat oleh puskesmas untuk meningkatkan kesehatan jiwa baik kepada individu dan keluarga di Kelurahan Balumbang Jaya menjadi latar belakang perlunya dilakukan penerapan terapi AT dalam meningkatkan kemampuan orang tua mengelola emosi anak. Oleh karena itu, penelitian ini dilakukan dengan tujuan dapat diperoleh gambaran tentang pengaruh Terapi kelompok Assertiveness Training terhadap kemampuan komunikasi orang tua dalam mengelola emosi anak usia sekolah (7-12 tahun) di Kelurahan Balumbang Jaya Bogor. 
Tabel 1. Perbedaan Kemampuan Komunikasi Asertif Ibu Sebelum dan Setelah Terapi Kelompok AT pada Kelompok Ibu yang Mendapat AT

\begin{tabular}{|c|c|c|c|c|c|c|c|}
\hline \multicolumn{2}{|c|}{ Kemamp uan } & \multirow{2}{*}{$\frac{\mathbf{N}}{32}$} & \multirow{2}{*}{$\begin{array}{c}\text { Mean } \\
44,13\end{array}$} & \multirow{2}{*}{$\begin{array}{c}\text { SD } \\
6,215\end{array}$} & \multirow[t]{2}{*}{$\mathbf{t}$} & \multirow[t]{2}{*}{ df } & \multirow[t]{2}{*}{$\mathbf{p}$} \\
\hline Kognitif & Sebelum & & & & & & \\
\hline & Sesudah & 32 & 65,75 & 4,886 & $-15,482$ & 31 & 0,000 \\
\hline & Selisih & & 21,62 & 1,329 & & & \\
\hline \multirow[t]{3}{*}{ Psikomotor } & Sebelum & 32 & 26,25 & 0,961 & & & \\
\hline & Sesudah & 32 & 45,50 & 0,935 & $-15,082$ & 31 & 0,000 \\
\hline & Selisih & & 19,25 & 0,026 & & & \\
\hline \multirow[t]{3}{*}{ Sikap } & Sebelum & 32 & 26,75 & 4,158 & & & \\
\hline & Sesudah & 32 & 39,94 & 2,327 & $-16,036$ & 31 & 0,000 \\
\hline & Selisih & & 13,19 & 1,831 & & & \\
\hline \multirow[t]{3}{*}{ Komposit } & Sebelum & 32 & 97,13 & 11,33 & & & \\
\hline & Sesudah & 32 & 151,19 & 8,148 & $-15,533$ & 31 & 0,000 \\
\hline & Selisih & & 54,06 & 3,186 & & & \\
\hline
\end{tabular}

\section{Metode}

Penelitian ini jenis quasi experimental dengan metode kuantitatif menggunakan desain "Quasi experimental pre-post test control group" dengan intervensi terapi kelompok terapeutik pada $24 \mathrm{Mei}$ sampai 22 Juni 2010. Teknik pengambilan sampel secara Cluster random sampling. Penelitian dilakukan untuk menganalisa peningkatan kemampuan komunikasi asertif ibu dalam mengelola emosi anak usia sekolah dan membandingkan antara kelompok yang mendapatkan dan yang tidak mendapatkan terapi kelompok Training. Tiap kelompok berjumlah 32 responden ibu dan anak usia sekolah. Analisis statistik yang dipergunakan yaitu univariat dan bivariat dengan analisis dependent dan independent sample t-Test serta Chi-square.

\section{Hasil}

\section{Kemampuan Komunikasi Asertif Ibu}

Penelitian dilakukan di Kelurahan Balumbang Jaya Kota Bogor terhadap 64 responden yaitu 32 respon- den yang mendapatkan terapi kelompok AT dan 32 responden tidak mendapatkan terapi kelompok AT.

Hasil analisis karakteristik ibu menunjukkan dari 64 orang ibu, rata-rata berusia 36 tahun dengan usia termuda 24 tahun dan tertua 55 tahun, pendidikan keluarga paling banyak pendidikan SD, SMP sebesar $89,06 \%$, pendapatan keluarga tiap bulannya rata-rata $\mathrm{Rp} 677.140,00$ dengan anak rata-rata 3 orang, jenis kelamin anak paling banyak laki-laki yaitu $54,6 \%$ dan status perkawinan ibu paling banyak adalah menikah sebesar $85,9 \%$.

Karakteristik ibu berdasarkan jenis kelamin anak, status perkawinan dan tingkat pendidikan antara kelompok intervensi dan kontrol sebelum mendapatkan terapi AT adalah sama/homogen, karena semua karakteristik memiliki $\mathrm{p}>0,05$. Setelah dilakukan terapi AT, kelompok yang mendapat terapi AT menunjukkan peningkatan kemampuan kognitif, psikomotor dan sikap lebih tinggi secara bermakna $(p<0,05)$ dibandingkan kelompok yang tidak mendapat terapi AT (lihat pada tabel 1). 
Tabel 2. Perbedaan Kemampuan Komunikasi Asertif Ibu Sebelum dan Setelah Terapi Kelompok AT pada Kelompok Ibu yang Tidak Mendapat AT

\begin{tabular}{|c|c|c|c|c|c|c|c|}
\hline \multicolumn{2}{|c|}{ Kemampuan } & \multirow{2}{*}{$\frac{\mathbf{N}}{32}$} & \multirow{2}{*}{$\begin{array}{c}\text { Mean } \\
37,75\end{array}$} & \multirow{2}{*}{$\frac{\text { SD }}{7,988}$} & \multirow[t]{2}{*}{$\mathrm{t}$} & \multirow[t]{2}{*}{ df } & \multirow[t]{2}{*}{$\mathbf{p}$} \\
\hline Kognitif & Sebelum & & & & & & \\
\hline & Sesudah & 32 & 33,31 & 6,864 & 9,741 & 31 & 0,000 \\
\hline & Selisih & & 4,437 & 1,124 & & & \\
\hline \multirow[t]{3}{*}{ Psikomotor } & Sebelum & 32 & 25,84 & 4,601 & & & \\
\hline & Sesudah & 32 & 24,59 & 4,825 & 3,536 & 31 & 0,001 \\
\hline & Selisih & & 1,250 & 0,224 & & & \\
\hline \multirow[t]{3}{*}{ Sikap } & Sebelum & 32 & 25,97 & 3,814 & & & \\
\hline & Sesudah & 32 & 24,44 & 2,816 & & 31 & 0,000 \\
\hline & Selisih & & 1,531 & 0,998 & & & \\
\hline \multirow[t]{3}{*}{ Komposit } & Sebelum & 32 & 89,56 & 16,40 & & & \\
\hline & Sesudah & 32 & 82,34 & 14,50 & & 31 & 0,0003 \\
\hline & Selisih & & 7,22 & 1,898 & & & \\
\hline
\end{tabular}

Kelompok yang mendapat terapi AT menunjukkan peningkatan kemampuan psikomotor lebih tinggi secara bermakna $(\mathrm{p}<0,05)$ dibandingkan kelompok yang tidak mendapat terapi AT. Sesudah mendapatkan terapi AT, kemampuan psikomotor ibu menjadi 45,5 (81,25\%). Dalam waktu 3 minggu terapi AT, terjadi kenaikan kemampuan psikomotor 34, $45 \%$ dari sedang ke tinggi. Butuh 18,75\% lagi untuk mencapai kemampuan psikomotor maksimum (lihat pada tabel 2).

Pada tabel 3 menunjukkan perbedaan kemampuan kognitif ibu dalam berkomunikasi asertif pada kelompok yang mendapat terapi AT lebih tinggi secara bermakna $(\mathrm{p}<0,05)$ dibandingkan kelompok yang tidak mendapat terapi AT. Naik sebanyak 21,62 poin atau naik sebesar $27 \%$. Sedangkan pada kelompok kontrol terjadi penurunan secara bermakna ( $\mathrm{p}<0,05)$, turun sebanyak 4,438 point atau turun sebesar $5,55 \%$.

Perbedaan kognitif antara kelompok yang mendapat dan tidak mendapat terapi AT sebesar 17,18 point $(21,45 \%)$ lebih tinggi pada kelompok yang mendapat terapi AT. Kemampuan sebelum terapi tidaksama/heterogen antara kedua kelompok, namun setelah mendapatkan terapi AT, terlihat bahwa kelompok intervensi menunjukkan selisih kenaikan yang cukup signifikan, naik dari sedang menjadi tinggi.

\section{Kemampuan Anak Mengelola Emosi}

Rerata kemampuan anak mengelola emosi sebelum ibu mendapat terapi AT adalah 50,55 dengan nilai terendah 36 dan tertinggi 71. Kelompok intervensi menunjukkan bahwa kemampuan anak mengelola emosi lebih tinggi adalah 51,19 (kemampuan sedang) dibandingkan dengan kelompok kontrol 49,91 (kemampuan rendah) (lihat pada tabel 4).

Kesetaraan kemampuan anak mengelola emosi sebelum ibu mendapat terapi kelompok AT pada kelompok intervensi dan kontrol dianalisis dengan uji $t$-test independent (tabel 5). Kemampuan anak mengelola emosi sebelum ibu mendapatkan terapi AT antara kelompok intervensi dan kontrol terdapat perbedaan yang kurang bermakna dengan $p>0,05$, 
Tabel 3. Perbedaan Kemampuan Komunikasi Asertif Ibu antara Kelompok yang Mendapat AT dan yang Tidak Mendapat AT

\begin{tabular}{|c|c|c|c|c|c|c|c|}
\hline Aspek & Kelompok & $\mathbf{N}$ & Mean & SD & $\mathbf{t}$ & $\mathbf{d f}$ & $\overline{\mathbf{p}}$ \\
\hline \multirow[t]{2}{*}{ Kognitif } & Intervensi & 32 & 65,57 & 4,886 & \multirow[b]{2}{*}{21,81} & \multirow[b]{2}{*}{62} & \multirow[b]{2}{*}{0,000} \\
\hline & Kontrol & 32 & 33,31 & 6,846 & & & \\
\hline \multirow[t]{2}{*}{ Psikomotor } & Intervensi & 32 & 45,50 & 5,292 & \multirow[b]{2}{*}{16,51} & \multirow[b]{2}{*}{62} & \multirow[b]{2}{*}{0,000} \\
\hline & Kontrol & 32 & 24,59 & 4,825 & & & \\
\hline \multirow[t]{2}{*}{ Sikap } & Intervensi & 32 & 39,94 & 2,327 & \multirow[b]{2}{*}{24,00} & \multirow[b]{2}{*}{62} & \multirow[b]{2}{*}{0,000} \\
\hline & Kontrol & 32 & 24,44 & 2,816 & & & \\
\hline \multirow[t]{2}{*}{ Komposit } & Intervensi & 32 & 151,19 & 12,50 & \multirow[b]{2}{*}{20,77} & \multirow[b]{2}{*}{62} & \multirow[b]{2}{*}{0,000} \\
\hline & Kontrol & 32 & 82,34 & 14,48 & & & \\
\hline
\end{tabular}

sehingga dapat disimpulkan bahwa tidak ada perbedaan/homogen antara kemampuan anak mengelola emosi sebelum ibu mendapatkan terapi AT pada kelompok intervensi dan kontrol (lihat tabel 6).

\section{Faktor yang Berkontribusi terhadap Kemampuan Komunikasi Asertif Ibu}

Hasil penelitian menunjukkan bahwa hubungan yang sangat kuat antara karakteristik ibu dan pemberian terapi Assertiveness Training terhadap peningkatan kemampuan kognitif $(\mathrm{r}=0,915)$, kemampuan psikomotor $(\mathrm{r}=0,844)$ dan sikap ibu $(\mathrm{r}=0,907)$. Karakteristik ibu dan pemberian terapi Assertiveness Training berpeluang meningkatkan kemampuan kognitif ibu dalam berkomunikasi asertif $83,8 \%$, berpeluang meningkatkan kemampuan psikomotor ibu 71,2\% dan berpeluang meningkatkan sikap ibu dalam berkomunikasi asertif $82,3 \%$. Hal ini menunjukkan kemampuan kognitif, psikomotor dan sikap orang tua dalam berkomunikasi secara asertif ke anak diperoleh dengan keterampilan berkomunikasi asertif melalui Assertiveness Training.

\section{Pembahasan}

Setelah tiga minggu mendapatkan terapi AT, kemampuan kognitif ibu naik sebesar 27\%, kemampuan psikomotor naik sebesar $34,45 \%$ sedangkan sikap ibu naik sebesar 28,7\%. Penelitian yang dilakukan oleh Alberti dan Emmons (1977) tentang pengaruh latihan asertif pada individu yang mengalami depresi. Penelitian yang berlangsung selama 32 hari melalui 11 sesi pada 64 orang responden, membuktikan terdapat pengaruh yang signifikant terhadap perubahan sikap dan konsep diri orang depresi $(\mathrm{p}<0,05)$.

Terapi AT mendukung orangtua memahami dan menanggapi segala respon emosi yang dimunculkan anak akibat dari kebutuhan anak yang tidak terpenuhi (Emmons, dalam Townsend, 2009). Dengan latihan asertif, orangtua melatih diri menerima emosi diri sendiri, menerima emosi anak, memikirkan dengan aktif cara menanggapi emosi anak. Orangtua akan memahami bahwa dengan cara agresif atau pasif setiap kali menghadapi keluhan anak, tidak membawa dampak yang positif pada hubungan orangtua dan anak (Gottman, J., \& DeClaire, 2008).

Setelah berdiskusi dengan para responden sebelum dilakukannya terapi AT, para ibu mengeluhkan sulitnya mengelola emosi anak dengan berbicara yang baik, ibu cenderung ingin mendapatkan hasil yang cepat, ingin anak segera memenuhi perihal yang diminta oleh ibu. Adanya keinginan dan kesadaran akan perubahan sikap ibu, dibutuhkan perubahan dari aspek kognitif terlebih dahulu. 
Tabel 4. Perbedaan Kemampuan Anak Mengelola Emosi Sebelum dan Setelah Ibu Mendapat Terapi AT pada Kelompok yang Mendapat dengan yang Tidak Mendapat AT

\begin{tabular}{lllclcl}
\hline & Kelompok & N & Mean & SD & t & p \\
\hline \multirow{2}{*}{ Intervensi } & Sebelum & 32 & 51,19 & 7,337 & & \\
& Sesudah & 32 & 80,59 & 7,448 & $-15,88$ & 0,000 \\
& Selisih & & 29,4 & 0,111 & & \\
\multirow{2}{*}{ Kontrol } & Sebelum & 32 & 49,91 & 6,331 & & 0,000 \\
& Sesudah & 32 & 47,94 & 6,390 & & \\
& Selisih & & $-1,94$ & 0,059 & & \\
\hline
\end{tabular}

Seperti yang dikatakan oleh Lewin, dkk (1987 dalam Gordon, 2009) bahwa anak-anak yang diasuh oleh orangtua yang otoriter banyak menunjukkan ciri-ciri sikap dan perilakunya terganggu, anak mudah menyerah. Karena itu butuh penelitian lebih lanjut tentang keterkaitan pola asuh terhadap kemampuan komunikasi asertif ibu.

Kunci keberhasilan terapi AT adalah kemampuan menjadi pendengar yang aktif, membutuhkan waktu hanya 5-10 menit untuk mendengar keluhan anak dengan penuh perhatian, mata sejajar dengan anak, berhadapan, rileks, dan menahan diri untuk memberikan nasihat ke anak. Proses ini sesuai terapi AT yang dilakukan oleh Alberti dan Emmons (1977) sebanyak 11 sesi.

Proses ini juga sesuai dengan yang dikatakan oleh Sobur (1993, dalam Ramadhani, 2008) bahwa komunikasi efektif antara orangtua dan anak adalah proses pemindahan informasi, ide, pengertian, pemahaman dari orangtua ke anak atau sebaliknya, kemudian diinterpretasikan sesuai dengan tujuan dan adanya saling pengertian antara kedua belah pihak. Sedangkan untuk kelompok yang tidak mendapat terapi AT, mengalami penurunan secara bermakna $(\mathrm{p}<0,05)$. Dalam waktu 3 minggu tidak mendapat terapi AT, kemampuan kognitif ibu turun $5,55 \%$, kemampuan psikomotor turun $2,2 \%$ dan sikap ibu turun $2,3 \%$.

Hasil penelitian menjelaskan pemberian terapi AT pada kelompok intervensi berdampak cukup besar pada pemahaman perilaku asertif secara kognitif. Sebaliknya jika tidak mendapatkan terapi AT dapat menurunkan ketiga ranah kemampuan ibu dalam mengelola emosi anak usia sekolah.

Penelitian Purwandari dan Purwanti (2008) tentang peningkatan kecerdasan emosi anak lewat pelatihan pembentukan karakter anak oleh guru di sekolah menunjukkan pengaruh yang signifikan $(\mathrm{p}=$ 0,05). Penelitian ini memperkuat hasil penelitian yang dilakukan pada orangtua melalui terapi AT. Terjadi peningkatan kognitif pada orangtua setelah dilakukan terapi AT, meliputi pemahaman gaya komunikasi asertif, mampu membedakan gaya komunikasi asertif, agresif dan pasif yang selama ini dilakukan oleh ibu ke anak.

Penelitian ini mendukung hasil penelitian yang dilakukan oleh peneliti hanya bedanya, penelitian yang dilakukan oleh Shapiro, Parush, Green, dan Roth (1997) dilakukan langsung ke anak dan penelitian yang dilakukan oleh peneliti saat ini meningkatkan kecerdasan emosi anak melalui pelatihan kemampuan kognitif, psikomotor dan sikap ibu dalam berkomunikasi secara asertif ke anak usia sekolah dengan terapi AT. Hasilnya terlihat terjadi peningkatan secara bermakna $(p<0,05)$.

Setelah dilatih, ibu menerapkan di rumah sebagai pelatih emosi anak, memberi contoh penyelesaian masalah ke anak dan menjadi pendengar aktif bagi keluhan anak. Sesuai dengan yang dikatakan Goleman (1996 dalam Nurjanah, 2008), 
Tabel 5. Kemampuan Anak Mengelola Emosi Sebelum dan Setelah Ibu Mendapat Terapi AT pada Kelompok yang Mendapat dengan yang Tidak Mendapat AT

\begin{tabular}{llllllll}
\hline & Kelompok & N & Mean & SD & t & df & p \\
\hline Intervensi & Sebelum & 32 & 51,19 & 7,33 & $-15,880$ & 31 & 0,000 \\
& Sesudah & 32 & 80,59 & 7,44 & & & \\
& Selisih & & 29,40 & 0,11 & & & \\
\multirow{2}{*}{ Kontrol } & Sebelum & 32 & 49,91 & 6,33 & 7,361 & 31 & 0,000 \\
& Sesudah & 32 & 47,94 & 6,39 & & & \\
& Selisih & & 1,969 & 0,05 & & & \\
\hline
\end{tabular}

bahwa kemampuan untuk memonitor, mengenali, dan memahami emosi sehingga dapat digunakan sesuai dengan situasi dan kondisi.

Orangtua dapat menjadi role model bagi anak dalam mengontrol emosinya ketika ada masalah (Gordon, 2009). Orang tua diyakini dapat mempengaruhi perilaku anak karena orangtua merupakan kelompok sosial pertama yang menjadi pusat identifikasi anak dan orang yang paling banyak menghabiskan waktu, berinteraksi dengan anak (Hurlock, 2008). Melalui proses belajar yaitu melihat, meniru dan melakukan apa yang dilakukan orangtuanya, anak mengadopsi perilaku orangtuanya.

\section{Kesimpulan}

Kemampuan ibu dalam berkomunikasi secara asertif sebelum mendapatkan terapi AT adalah sedang, sedangkan kemampuan anak mengelola emosinya sebelum ibu mendapatkan terapi AT adalah sedang. Kemampuan ibu berkomunikasi asertif meningkat secara bermakna $(p<0,05)$ dari sedang ke tinggi setelah mendapat terapi AT. Kemampuan anak mengelola emosi meningkat secara bermakna $(\mathrm{p}<0,05)$ dari sedang ke tinggi setelah mendapatkan terapi AT.

Terapi kelompok AT berpeluang dalam meningkatkan kemampuan kognitif, psikomotor, dan sikap ibu dalam berkomunikasi asertif. Aspek kognitif sebesar $83,8 \%$, aspek psikomotor sebesar $71,2 \%$, dan aspek sikap ibu sebesar $82,3 \%$ setelah dikontrol oleh faktor lain. Kemampuan kognitif, psikomotor, dan sikap ibu dalam berkomunikasi secara asertif terhadap anak usia sekolah dipengaruhi oleh karakteristik ibu dan terapi AT itu sendiri secara bermakna $(p<0,05)$.

Tindak lanjut terhadap hasil penelitian diperlukan agar dapat dimanfaatkan semaksimal mungkin. Dinas kesehatan bekerja sama mahasiswa Spesialis keperawatan jiwa melakukan pelatihan kepada perawat puskesmas khususnya yang bertanggung jawab terhadap pelayanan kesehatan jiwa untuk diterapkan di wilayah kerja masingmasing.

Tabel 6. Perbedaan Kemampuan Anak Mengelola Emosi antara Kelompok Ibu yang Mendapat Terapi AT dengan yang Tidak Mendapat AT

\begin{tabular}{|c|c|c|c|c|c|c|}
\hline Kelompok & $\mathbf{N}$ & Mean & SD & $t$ & df & $\mathbf{p}$ \\
\hline Intervensi & 32 & 80,59 & 7,448 & \multirow{2}{*}{18,82} & \multirow{2}{*}{62} & \multirow{2}{*}{0,000} \\
\hline Kontrol & 32 & 47,94 & 6,390 & & & \\
\hline
\end{tabular}


Supervisi yang mempunyai jenjang dan terjadwal untuk pelaksanaan terapi kelompok AT juga diperlukan agar dapat diketahui efektivitasnya. Terapi kelompok AT dapat dijadikan sebagai salah satu kompetensi yang harus dilakukan pada pelayanan kesehatan jiwa di masyarakat (berbasis komunitas) oleh perawat spesialis keperawatan jiwa. Hasil penelitian ini perlu diteliti lebih lanjut terkait faktor perancu lain yang mempengaruhi keberhasilan terapi kelompok terapi AT (DN, AY, RR).

\section{Referensi}

Alberti, R.E., \& Emmons, M.L. (1977). Assertiveness: innovation, explanations, issues, and impact. San Luis: Impact Publisher.

Gordon, T. (2009). Menjadi orang tua efektif mendidik anak agar bertanggung jawab (Edisi 13). Jakarta: PT Gramedia Pustaka Utama.

Gottman, J., \& DeClaire, J. (2008). Mengembangkan kecerdasan emosional anak (Edisi 1). Jakarta : PT. Gramedia Pustaka Utama.

Hartono, A. (2009). Emotional quality parenting: Cara praktis menjadi orang tua pelatih emosi (Edisi 1). Jakarta: PT Gramedia Pustaka Utama.
Hurlock, E. (2008). Perkembangan anak jilid 1 (Edisi 6). Jakarta: Erlangga.

Ibung, D. S. (2008). Panduan praktis bagi orangtua dalam memahami dan mendampingi anak usia 6-12 tahun (Edisi 1). Jakarta: Elex Media Komputindo.

Purwandari, E., \& Purwati. (2008). Character building: pengaruh pendidikan nilai terhadap kecerdasan emosi anak. Jurnal Penelitian Humaniora, 9 (1), 13-31.

Ramadhani, S. (2008). The art of positive communicating, mengasah potensi dan kepribadian positif pada anak melalui komunikasi positif (Edisi 1). Yogyakarta: Book Marks.

Stuart, G.W., \& Laraia, M.T. (2005). Principles and practice of psychiatric nursing (8th Ed.). St. Louis: Mosby, Inc.

Shapiro, M., Parush, S., Green, M., \& Roth, D. (1997). The efficacy of the 'Snoezelen' in the management of children with mental retardation who exhibit maladaptive behaviours. British Journal of Developmental Disabilities, 43, 140-155.

Townsend, M.C. (2009). Psychiatric mental health nursing: Concepts of care in evidence-based practice (6th Ed.). Philadelphia: F.A. Davis Company. 